\title{
Effects of Sampling between Data of Significant Wave Height for Intensity and Duration of Severe Sea Storms
}

\author{
Felice Arena", Valentina Laface, Giuseppe Barbaro, Alessandra Romolo \\ Natural Ocean Engineering Laboratory, Department of Civil Engineering, Energy, Environment and Materials, \\ Mediterranea University, Reggio Calabria, Italy \\ Email: ${ }^{*}$ arena@unirc.it
}

Received November 21, 2012; revised December 19, 2012; accepted January 13, 2013

\begin{abstract}
The paper deals with the analysis of severe storms in the central Mediterranean Sea and in the US coasts of the Atlantic and Pacific Ocean. Firstly, we introduce a model for the representation of the sea storms by means of two parameters: the former is given by the maximum value of significant wave height in the actual storm and defines the storm intensity, the latter gives the storm duration. The analysis considers buoy data with different sampling $\Delta t$ between two consecutive records, which varies in the range $0.5-6$ hours. The sensitivity analysis of the modelled sea storm with the variation of $\Delta t$ shows as the structure of storms is strongly modified with large values of $\Delta t$ of order of 3 - 6 hours: both the intensity and the duration may change significantly. The results are of interest to investigate the extreme events in the storms obtained with WAve Model, starting from meteorological data, where the value of $\Delta t$ of 6 hours is widely applied. The conclusion is that structure of severe storms should be represented with continuous data, with $\Delta t=0.5$ hours; a good representation is also obtained with $\Delta t=1$ hour. The errors with increasing values of $\Delta t$ are investigated.
\end{abstract}

Keywords: Sea Storm; Wave; Storm Duration; Storm Intensity

\section{Introduction}

A sea storm is a sequence of sea states, in which the significant wave height exceeds a fixed threshold, whose value depends on the considered location [1-3]. In the Mediterranean Sea, the storm threshold may be considered even equal to $1.5 \mathrm{~m}$ : this value cannot be considered in most locations in the oceans. A general definition of sea storm was proposed by Boccotti [4-7].

Statistical properties of waves in a sea storm were investigated by Borgman [8,9], who determined the cumulative distribution function of the maximum wave height in a sea storm through an integral form. This result is very important for long-term analysis of extreme waves, based on the concept of extremes during a sea storm. For example, the Equivalent Triangular Storm model [4], as well as the Equivalent Power Storm model [10], represents a storm by means of two parameter: the former giving the intensity of the storm, the latter the duration of the storm.

Both models enable to determine, with an analytical approach, the long-term statistics of severe storms [4-7, 10]. A key parameter for these approaches is given by the storm duration, which is estimated by starting from the sequence of storms in a given location (considering a time span greater than several years).

\footnotetext{
${ }^{*}$ Corresponding author.
}

In this paper some storms are investigated, both in the Central Mediterranean Sea and in the Atlantic and $\mathrm{Pa}-$ cific Ocean. Data of Italian buoys network and of NOAA-National Data Buoy Center (USA) are processed.

The storm analysis is proposed by considering different values of the sampling $\Delta t$ between two consecutive records, varying in the range $(0.5-6$ hours $)$. The sensitivity analysis of the model with the variation of $\Delta t$ is proposed, to determine how this time interval modifies the intensity and the duration of the sea storms. Finally, some comments are given on the effect of the results on long-term modeling by applying the equivalent storm approaches [4-7,10,11].

\section{Sea Storms}

A sea storm is defined as a sequence of sea states in which the significant wave height $H_{s}$ exceeds a given threshold. In general, the storm starts when $H_{s}$ has an up-crossing related to the given storm threshold and ends when $H_{s}$ goes down this threshold.

Following Boccotti [4], we may define a sea storm as "a sequence of sea states in which the significant wave height exceeds the threshold $h_{c r i t}$ and does not fall below this threshold for a continuous time interval greater than 12 hours".

This storm definition enables to take into account that 
a "calm" period may occur even during a storm: if this period, in which $H_{s}$ is below the threshold $h_{c r i t}$, has duration smaller than 12 hours we have a single storm. If this time is greater than 12 hours, we consider two different storms.

Regarding the storm threshold, it must depend upon the given location. It may be considered proportional to the average value $H_{s}$ of the significant wave height. Boccotti [4-7] proposed a storm threshold equal to 1.5 times $H_{s}$. A higher value of this threshold, for example 2 or 3 times $H_{s}$ may be assumed: in this case we have a lower number of storms.

\subsection{Statistical Properties of Waves in a Sea Storm}

Let us consider a storm given by a sequence of $N_{s}$ sea states, with different values of significant wave height and peak/mean period.

The cumulative distribution function, defined as the probability to have the maximum wave height in the sea storm smaller than a given threshold $H$ is given by:

$$
P\left(H_{\max }<H\right)=\prod_{i=1}^{N_{s}}\left[1-P\left(H ; H_{s}=h_{i}\right)\right]^{D_{t} / \bar{T}(h i)}
$$

where $D_{t}$ is the sea state duration, $\bar{T}$ the mean period [12] and

$$
P\left(H ; H_{s}=h\right)=\exp \left[-\frac{4}{1+\psi^{*}}\left(\frac{H}{h}\right)^{2}\right]
$$

[4] is the probability that a wave has height larger than $H$ in a sea state with significant wave height $H_{s}$ equal to $h$. The narrow bandedness parameter $\psi^{*}$ is the ratio, in absolute value, between the absolute minimum and the absolute maximum of the covariance function of the sea state. The parameter $\psi^{*}$ is equal to 1 for an infinitely narrow spectrum, 0.73 for a mean JONSWAP spectrum [13] and 0.65 for a Pierson-Moskowitz spectrum [14].

Following Borgman [8,9], Equation (1) may be rewritten in the integral form as

$$
P\left(H_{\max }<H\right)=\exp \left\{\int_{0}^{D} \frac{\ln \left[1-P\left(H ; H_{s}=h(t)\right)\right]}{\bar{T}[h(t)]} d t\right\}
$$

where $D$ is the storm duration.

The maximum expected wave height $\overline{H_{\max }}$ in the sea storm is achieved as the integral over $(0, \infty)$ of the probability of exceedance $1-P\left(H_{\max }<H\right)$.

\subsection{Bi-Parametric Models for Sea Storms}

Sea storms may be obtained from a time series of significant wave height at a given location. Then, a bi-parametric model may be applied to determine the properties of each storm: the former will define the intensity of the storm; the latter the duration.

\subsubsection{Equivalent Triangular Storm Model}

The ETS model associates a triangle to each actual storm. The height $a$ of the triangle represents the storm intensity and is equal to the maximum significant wave height during the actual storm. The base $b$ of the triangle represents the storm duration, and it is such that the maximum expected wave height is the same in the actual storm and in the triangular storm.

Note that the height $a$ is achieved from the storm history directly, whereas the base $b$ is determined with an iterative procedure. Starting from the calculated value of the expected wave height in the actual storm $\overline{H_{\max }}$, and from the height $a$ of the ETS, we fix a tentatively value $b$ ' of the base of the ETS in order to calculate:

$$
\overline{H_{\max }}\left(a, b^{\prime}\right)=\int_{0}^{\infty} 1-\exp \left\{\frac{b^{\prime}}{a} \int_{0}^{a} \frac{\ln \left[1-P\left(H ; H_{s}=h\right)\right]}{\bar{T}(h)} d h\right\} d H
$$

which is the maximum expected value of the wave height in a triangular storm with height $a$ and base $b^{\prime}$.

Then, if $\overline{H_{\max }}$ of the actual storm is greater than $\underline{H_{\max }}\left(a, b^{\prime}\right)$, the base $b$ will be greater than $b^{\prime}$; if $\overrightarrow{H_{\max }}<\overline{H_{\max }}\left(a, b^{\prime}\right)$, then $b<b^{\prime}$.

The ETS model was introduced by Boccotti [4] for the long-term statistics of ocean waves and then applied by Arena \& Pavone [6,7] for the long-term modeling of nonlinear crest heights and for the achievement of a generalized approach for extreme waves during storms.

\subsubsection{Equivalent Power Storm Model}

The Equivalent Power Storm model generalizes the concept of triangular storm: the significant wave height in time domain, during a storm, is represented with a $\lambda$ power law $(\lambda>0)$, as

$$
H_{s}(t)=a\left[1-\left(2 t / b_{\lambda}\right)^{\lambda}\right], \text { for }-b / 2 \leq t \leq b / 2
$$

where the peak of the storm (equal to $a$ ) occurs at $t=0$. For a given value of $\lambda$, the EPS is defined by means of the height $a$ and the base $b_{\lambda}$ which is achieved through the iterative procedure described for the ETS (see section (2.2.1)).

The maximum expected wave height in a power $\lambda$ storm with height $a$ and base $b_{\lambda}$, is

$$
\int_{0}^{\infty} 1-\exp \left\{\frac{b}{\lambda a} \int_{0}^{a} \frac{\ln \left\{1-P\left(H \mid H_{s}=h\right)\right\}}{\bar{T}(h)}\left(1-\frac{h}{a}\right)^{1 / \lambda-1} d h\right\} \mathrm{d} H .
$$

The EPS model was introduced by Fedele \& Arena [10] to give a better representation of the storms, and for the extreme values of wave heights. They showed that the EPS model has a good stability for $\lambda>0.7$. Furthermore, 
the value of $\lambda$ characterizes the storm: we have a parabolic storm for $\lambda=2$, a cubic storm for $\lambda=3$, a cuspstorm for $\lambda=0.5$ and so on. For $\lambda=1$ we have triangular storms. Fedele \& Arena [10] showed that the optimal value $\lambda$, for the modeling of extreme sea storms, is 0.75 .

\subsection{Application of ETS and EPS Models for Long-Term Modeling of Extreme Storms}

Let us consider the return period $R\left(H_{s}>h\right)$ of a sea storm in which the maximum significant wave height is greater than $h$. The solution for $R\left(H_{s}>h\right)$, by considering the EPS model, was derived by Fedele and Arena [7]. It is given by the equation

$$
R\left(H_{s}>h\right)=\frac{1}{\int_{h}^{\infty} \frac{a}{\bar{b}(a)} G(\lambda, a) d a}
$$

where $\bar{b}(a)$ is the mean base for given height $a$ (which provides the relation between the mean value of the bases $b$ and the heights $a$ of the EPSs by means of a regression) and $G(\lambda, a)$ is a function related to the probability density function of the EPS heights.

The expression of $\bar{b}(a)$ is highly dependent on the location under examination. Analysis of several data has shown that the mean base-height regression formula

$$
\bar{b}(a)=K_{b} \exp \left(\frac{a}{K_{a}}\right)
$$

may be applied for estimation of $R\left(H_{s}>h\right)$, where $K_{a}$ and $K_{b}$ are location-dependent parameters; note that $K_{a}$ is a length like $a$, and $K_{b}$ has the dimension of time (it is in hours if $b$ is in hours). The function $G(\lambda, a)$ is defined in [10].

Equation (8) is very important for the calculation of return values of significant wave height for fixed values of the return period. Then, analysis of the variability of the storm bases, and then of the regression (8) is important for applications.

\section{Analysis of Severe Storms, Recorded by NOAA (USA) and RON (Italy) Buoys}

In the paper some buoys are considered from both the NOAA-NDBC (National Oceanic and Atmospheric Administration's - National Data Buoy Center) network (USA) and the Italian buoys network (RON-Rete Ondametrica Nazionale - managed by ISPRA).

The NOAA manages the NDBC, which consists of a network with many buoys moored along the US coasts, both in the Pacific Ocean and in the Atlantic Ocean. Some buoys were moored in the seventies, so that more than 30 years of data are available. The historical wave data consists in significant wave height, peak and mean period, given with a sampling between two consecutive records equal to one hour. Only few buoys are directional.

In the paper the NOAA buoys 46066, 46028, 46035, 46085, 46001 are considered in the Pacific Ocean and the buoys 41048, 44001, 44005, 44008, 44011 in the Atlantic Ocean.

The Italian buoys network (RON) started measurements in 1989, with 8 directional buoys located off the coasts of Italy. Currently, the network consists of 15 buoys, moored in deep water. The time $\Delta t$ between two consecutive records, during storms, is half an hour; for each record, the data of significant wave height, peak and mean period and dominant direction are given. In the Central Mediterranean Sea, the buoys of Alghero, Mazara del Vallo, Ponza, Cetraro and Crotone are considered.

\subsection{Data Analysis}

The analysis of severe sea storms in the Mediterranean Sea and in the Atlantic and Pacific Ocean is proposed by processing as input data the significant wave height time series, respectively, from both buoys of RON network and buoys of the NOAA.

The analysis is carried out by applying both the equivalent triangular storm (ETS) model and the equivalent power storm (EPS) model, assuming different values of the time intervals $\Delta t$ between two consecutive records. It is considered a $\Delta t$ value ranging between 0.5 and 6 hours for the RON data, and between 1 and 6 hours for the NDBC data.

In the Mediterranean Sea, the strongest storm recorded from 1989 to 2005 has been identified and analyzed, for each location. For Alghero, which is characterized by the severest wave climate in Italian Sea, 25 storms have been processed.

For the Atlantic and Pacific Ocean, 10 buoys have been considered and for each of them, the most intense storm recorded during the last three years has been identified and analyzed.

For the most severe actual storm, recorded at each considered location, both in the Mediterranean sea and in the Oceans, the Equivalent Triangular Storm $(\lambda=1)$ and the Equivalent Power Storm (for values of the shape parameter $\lambda$ equal to $0.5,0.75,2,3)$ have been determined by considering a time interval $\Delta t$ between two consecutive records equal to $1,3,6$ hours. These elaborations are given in Figure $\mathbf{1}$ for five storms of the NDBC-NOAA buoys and in Figure 2 for five buoys of the RON storms. We may appreciate the sensitivity of the base and the height of each storm for increasing value of $\Delta t$ of interest for application (that is $\Delta t$ up to 6 hours, which is a value widely used in meteorological models).

All data have been processed in order to achieve the intensity and duration of the sea storms.

It is found, in agreement with [10], that $b$ decreases for 


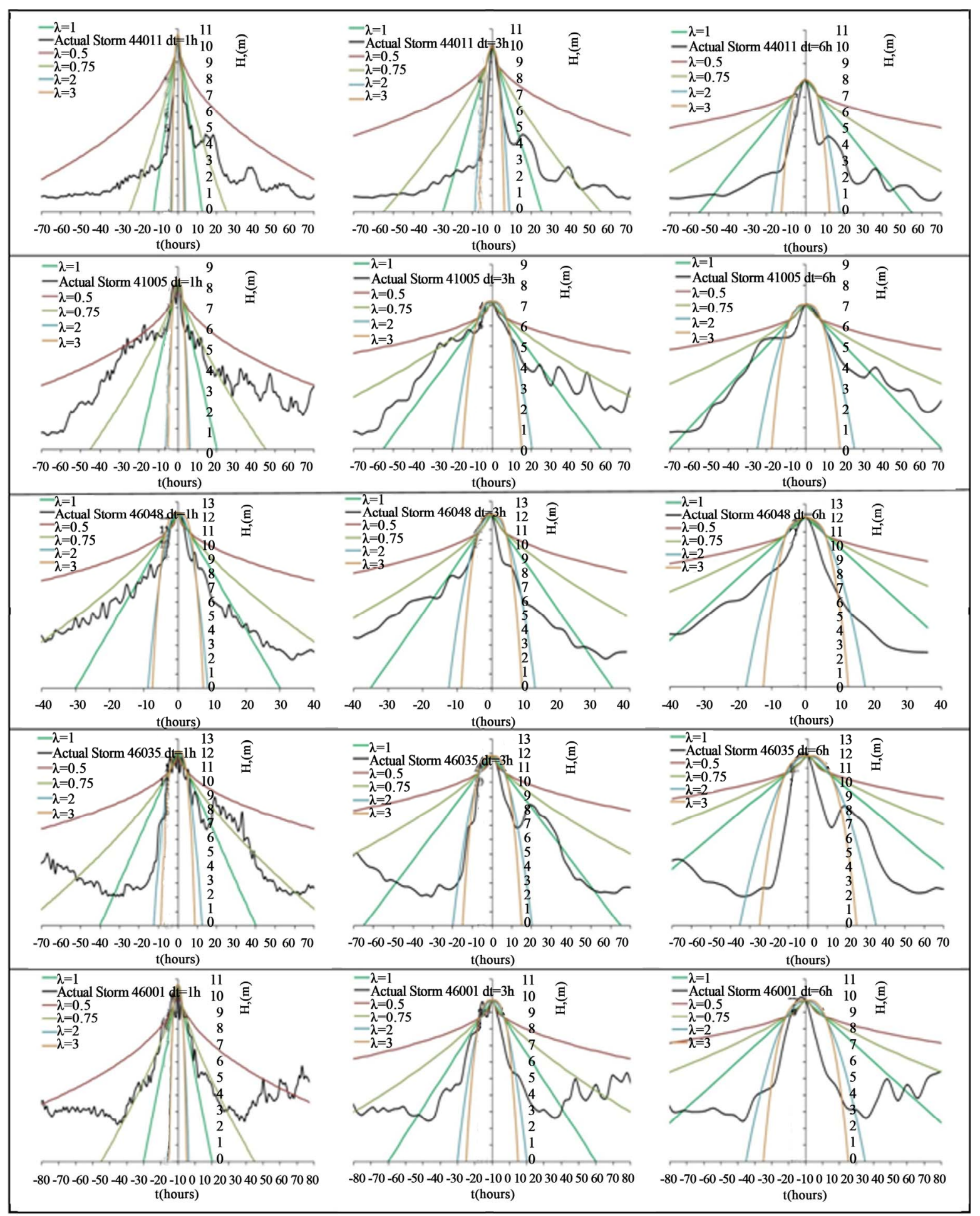

Figure 1. Five storms recorded by NOAA-NDBC buoys in the Atlantic and Pacific Oceans. They are the severest storms recorded at the considered buoys in the last three years, and the relative EPS calculated for different values of $\lambda$, between 0.5 and 3. First column shows each storm obtained for a time span between two records of 1 hour; the second and third columns show the storm for 3 and 6 hours respectively.

increasing values of $\lambda$. This is a systematic trend, observed from all storms.

Regarding the effect of variation of time $\Delta t$ between two successive records, we have found that the mean base $b_{m}$ of the storm increases for increasing values of $\Delta t$. Table 1 summarizes these results: we may compare the 


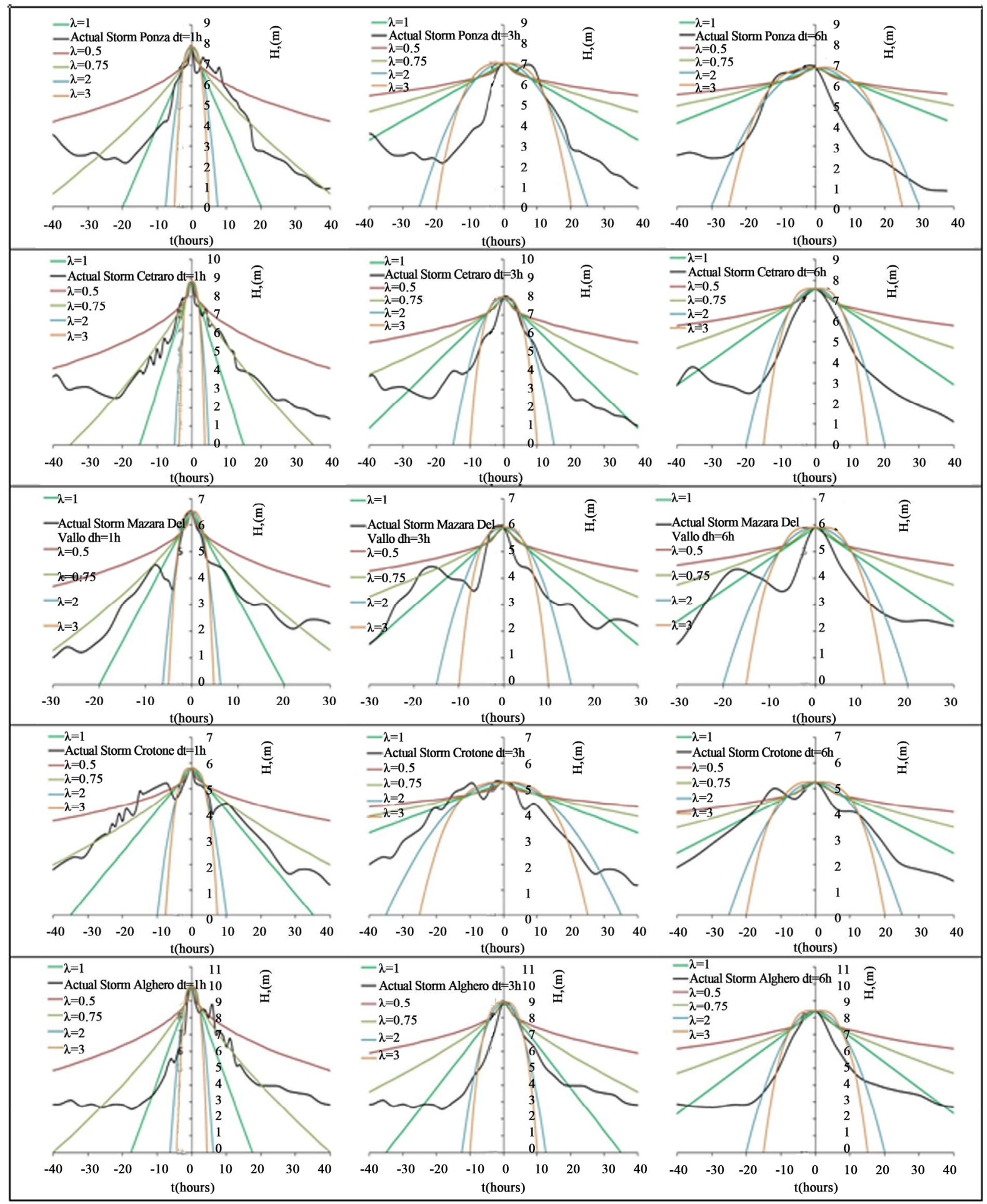

Figure 2. Five storms recorded by RON buoys in the Central Mediterranea Sea. They are the severest storms recorded at the considered buoys in the last three years, and the relative EPS calculated for different values of $\lambda$, between 0.5 and 3 . First column shows each storm obtained for a time span between two records of 1hour; the second and third columns show the storm for 3 and 6 hours respectively.

mean values of the storm duration, for a given values of $\lambda$, for different $\Delta t$.

Note that the analysis has been carried out starting from the smallest values of $\Delta t$ available from significant wave height time series (that is $\Delta t=0.5$ hours for RON buoys and $\Delta t=1$ hour for NOAA buoys). To increase the 
value of $\Delta t$ the data has been partially analyzed: starting from the full time series, with $\Delta t=0.5$ hours for RON, the analysis for $\Delta t=1$ hour is done by considering a value of $H_{s}$ every two, for $\Delta t=3$ hours a value of $H_{s}$ every six and so on. Each time series, with a given value of $\Delta t$, has been then processed to analyze the properties of the storm.

In the Figure 3, a scatter diagram is shown with the duration (parameter $b$ of the associated equivalent storm), for the whole set of analyzed storms recorded at the considered locations, which has been calculated with different values of the time interval $\Delta t$ between two consecutive records, for any fixed value of the shape parameter $\lambda$. We observe that, for both the Mediterranean and the Oceans, the duration of a sea storm tends to increase as greater $\Delta t$ is.

In Figure 4 the analysis of the storm duration when the interval $\Delta t$ between two consecutive records varies, has been carried out for Alghero by considering the 25 most intense storms. It is confirmed that for fixed sea
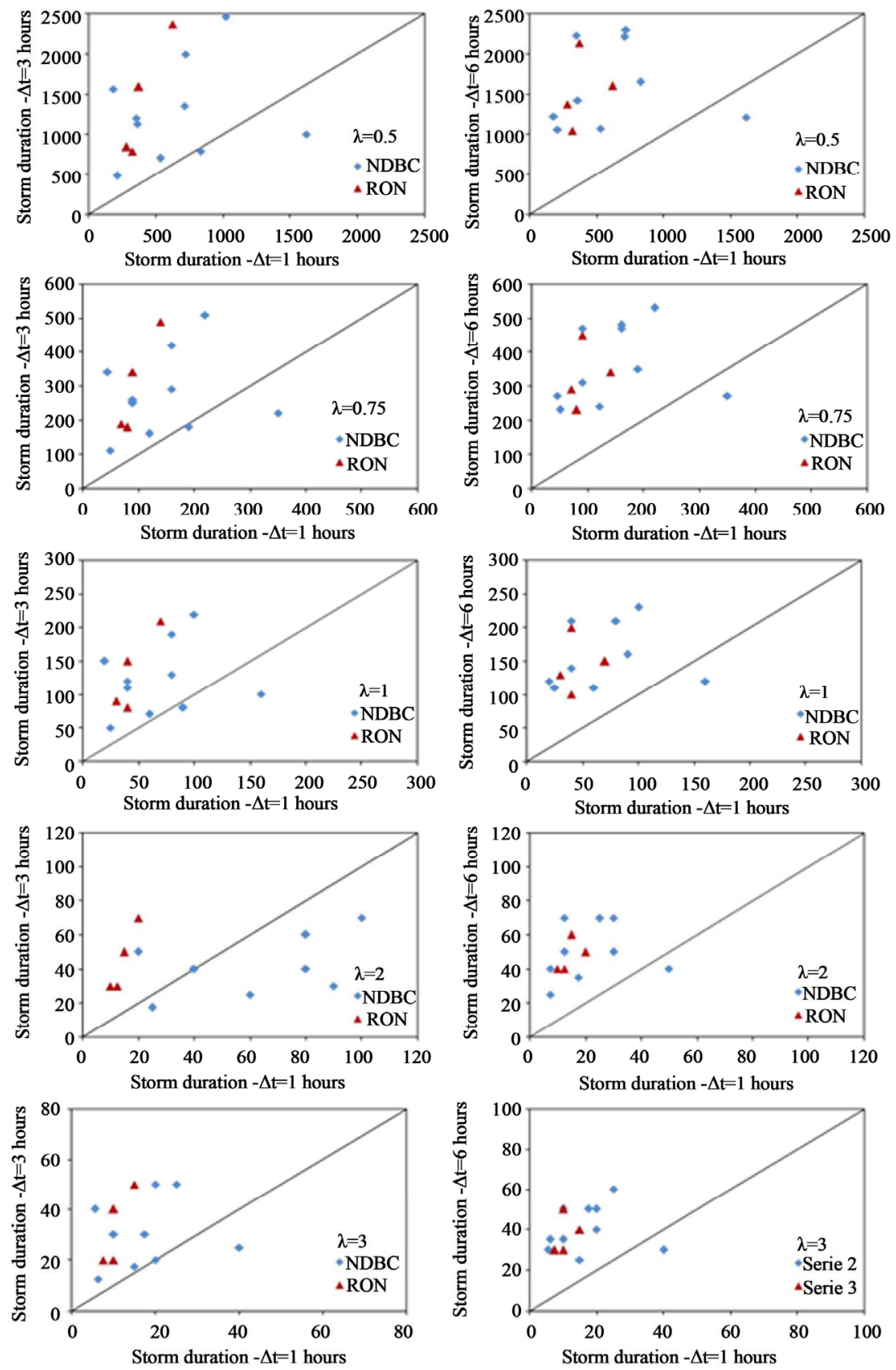

Figure 3. Duration of the most intense storms recorded at the considered buoys of the NOAA- NDBC and of the RON, calculated with different values of the time interval $\Delta t$ between two consecutive records, for a fixed value of the shape parameter $\lambda$. 

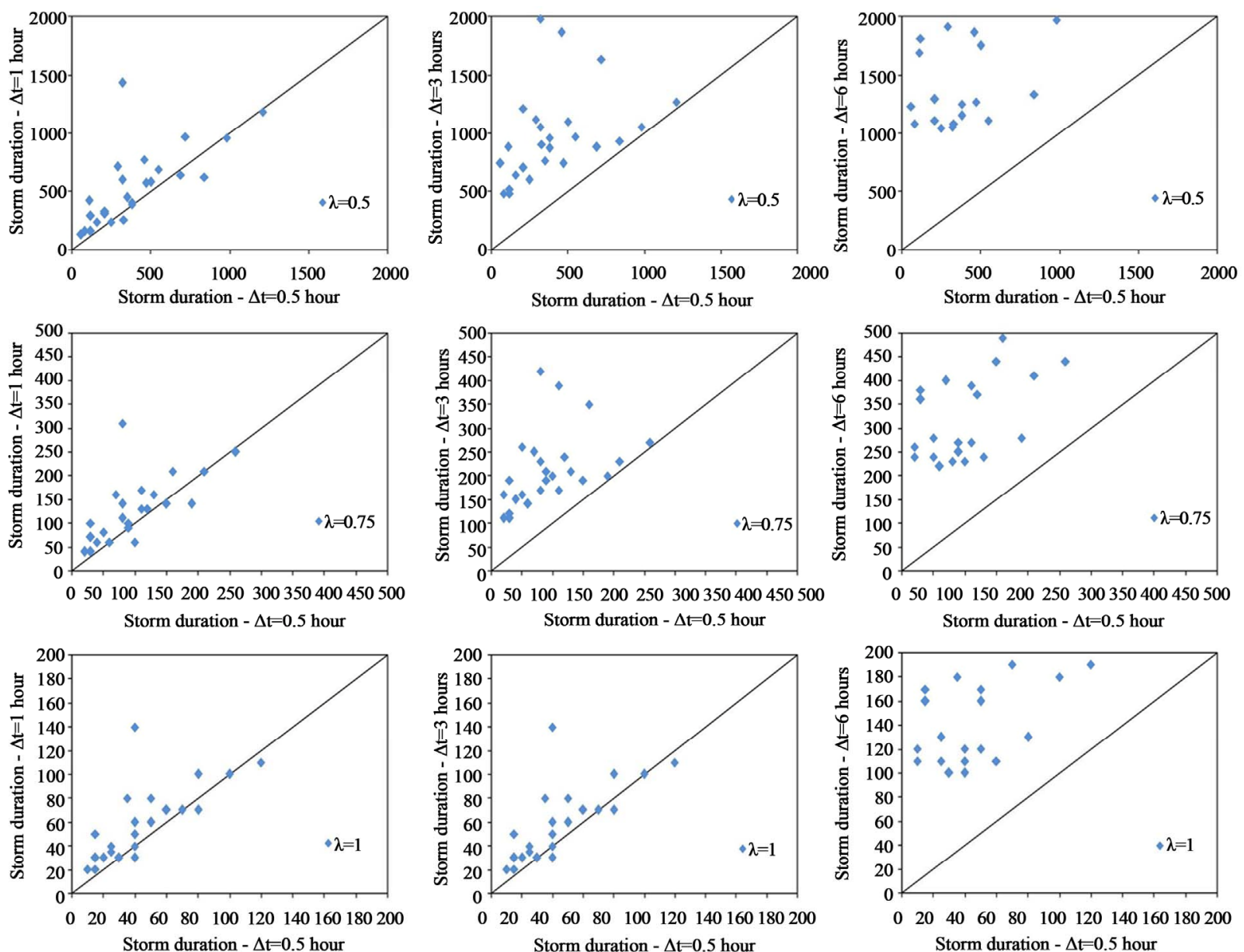

Storm duration $-\Delta t=0.5$ hour
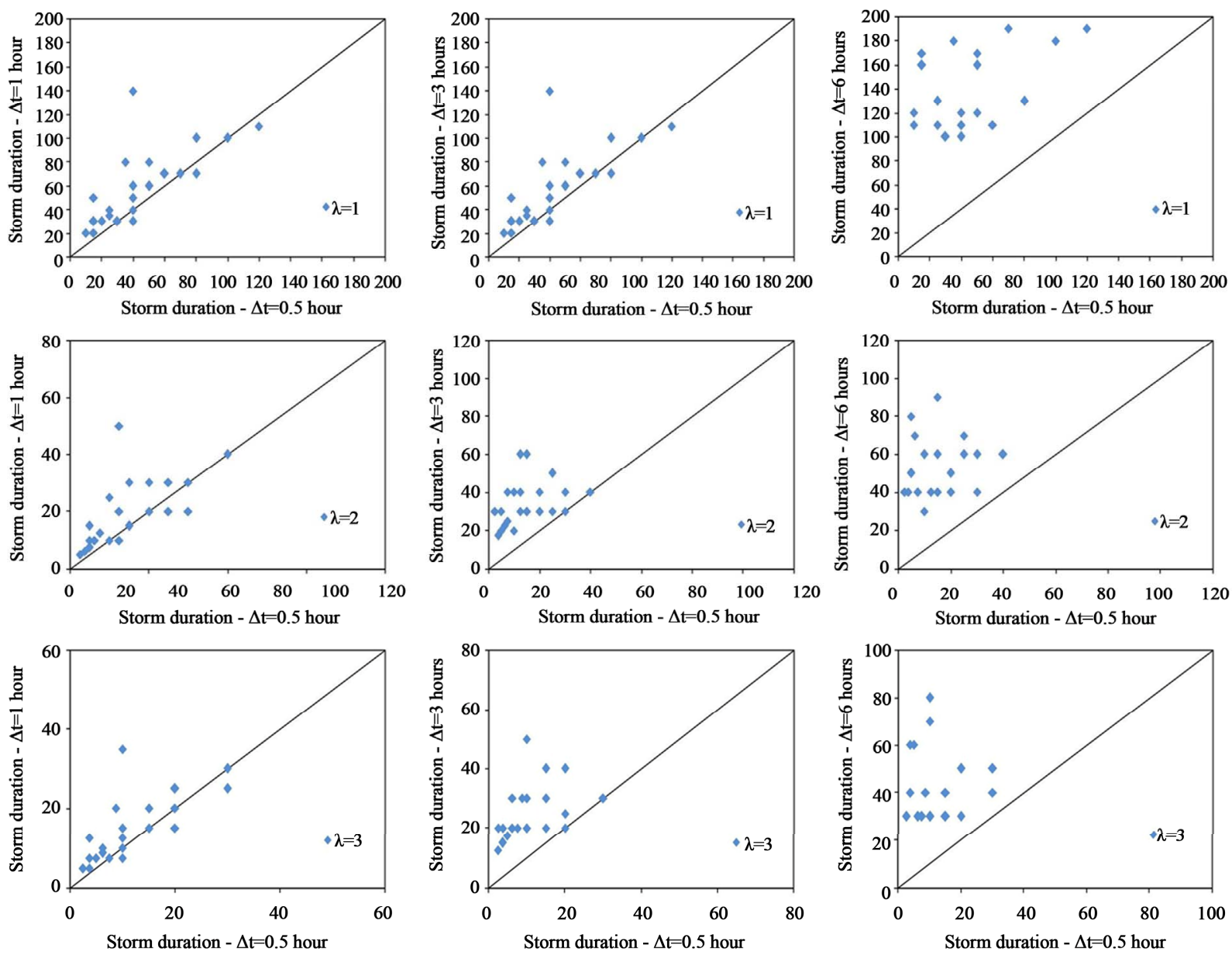

Figure 4. Duration of the 25 most intense storms recorded at Alghero (Italy by the RON), calculated with different values of the time interval $\Delta t$ between two consecutive records, for a fixed value of the shape parameter $\lambda$.

storm, its duration grows when $\Delta t$ increases.

For what concerns the storm intensity (parameter $a$ of the associated equivalent storm), from Figure 5 it is evident that, considering a time interval between two con- 
Alghero storms
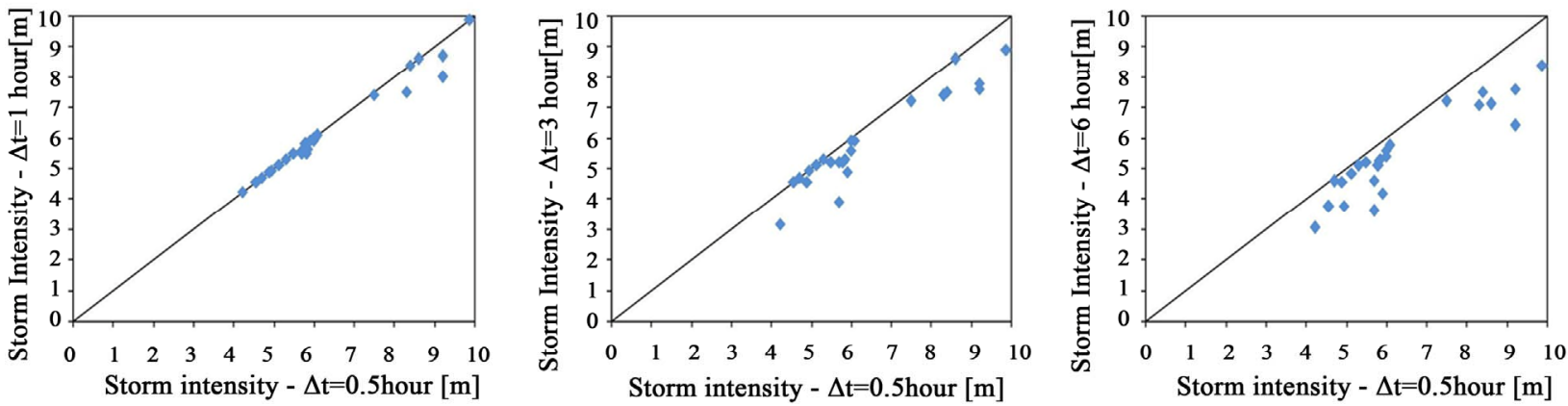

NOAA-NDBC buoys, RON buoys
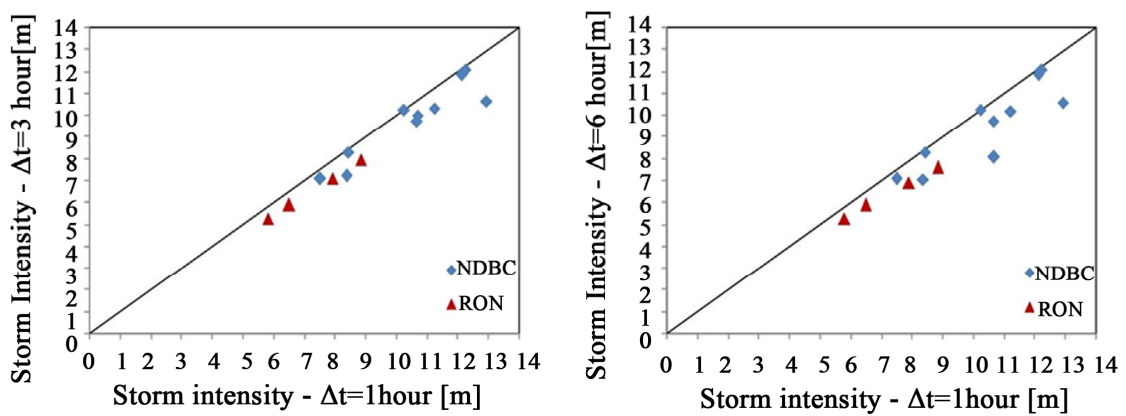

Figure 5. Intensity of storms for different values of time $\Delta t$ between two consecutive records. (a) Alghero buoy; (b) NOAA-NDBC and RON buoys.

Table 1. Mean values $b_{m}$ of the storm duration, for a given values of $\lambda$, for different $\Delta t$.

\begin{tabular}{|c|c|c|c|c|}
\hline \multirow[b]{2}{*}{$\lambda=0.5$} & \multicolumn{4}{|c|}{$b_{m}$ [hours] } \\
\hline & $\Delta t=0.5 \mathrm{~h}$ & $\Delta t=1 \mathrm{~h}$ & $\Delta t=3 \mathrm{~h}$ & $\Delta t=6 \mathrm{~h}$ \\
\hline Alghero & 404.4 & 540.4 & 972.8 & 1760.4 \\
\hline RON & 307.5 & 397.5 & 1397.5 & 1537.5 \\
\hline NDBC & - & 653.0 & 1266.0 & 1692.0 \\
\hline$\lambda=0.75$ & $\Delta t=0.5 \mathrm{~h}$ & $\Delta t=1 \mathrm{~h}$ & $\Delta t=\mathbf{3} \mathbf{h}$ & $\Delta t=6 \mathrm{~h}$ \\
\hline Alghero & 94.4 & 123.2 & 212.8 & 370.8 \\
\hline RON & 72.5 & 95.0 & 300.0 & 327.5 \\
\hline NDBC & - & 147.5 & 274.0 & 362.0 \\
\hline$\lambda=1$ & $\Delta t=0.5 \mathrm{~h}$ & $\Delta t=1 \mathrm{~h}$ & $\Delta t=3 \mathrm{~h}$ & $\Delta t=6 \mathrm{~h}$ \\
\hline Alghero & 44.0 & 57.8 & 95.6 & 163.6 \\
\hline RON & 37.5 & 45.0 & 132.5 & 145.0 \\
\hline NDBC & - & 69.5 & 122.0 & 162.0 \\
\hline$\lambda=2$ & $\Delta t=0.5 \mathrm{~h}$ & $\Delta t=1 \mathrm{~h}$ & $\Delta t=\mathbf{3} \mathbf{h}$ & $\Delta t=6 \mathrm{~h}$ \\
\hline Alghero & 14.8 & 19.2 & 33.4 & 62.0 \\
\hline RON & 12.5 & 14.4 & 45.0 & 47.5 \\
\hline NDBC & - & 21.8 & 40.3 & 52.0 \\
\hline$\lambda=\mathbf{3}$ & $\Delta t=0.5 \mathrm{~h}$ & $\Delta t=1 \mathrm{~h}$ & $\Delta t=3 \mathrm{~h}$ & $\Delta t=6 \mathrm{~h}$ \\
\hline Alghero & 11.6 & 14.8 & 25.4 & 40.8 \\
\hline RON & 9.4 & 10.6 & 32.5 & 37.5 \\
\hline NDBC & - & 17.0 & 30.5 & 40.5 \\
\hline
\end{tabular}

secutive records greater than 1 hour, the peak of the storm is not always well identified. The maximum significant wave height can be smaller than that one actually occurred at the apex of the storm. This difference increases as greater $\Delta t$ is.

\section{Conclusions}

The paper has shown the comparison among some severe storms, recorded by buoys of NOAA-NBDC network in the Atlantic and Pacific Oceans and by RON Italian network, in the Central Mediterranean Sea. The equivalent power storm (EPS) model has been applied for representing the storms by means of a given power law, which may be linear (with $\lambda=1$ power), giving a triangular storm, or a parabolic $(\lambda=2)$, a cubic $(\lambda=3)$, a cusp $(\lambda=$ $0.5)$ storm.

It has been shown how the structure of the storms changes with different values of the time span $\Delta t$ between two following records. The RON gives actually records each 0.5 hours, while the NOAA-NODC each hour.

The variability of the intensity and duration of the storms, represented with the EPS model, has been investtigated, for increasing value of time $\Delta t$ between two records in the range (0.5, 6 hours). Value of 6 hours is widely used for analysis of significant wave heights from 
meteorological models (for example, the WAMECMWF).

The result is that for increasing values of $\Delta t$ two variations (errors) appears: the storm duration is increased significantly, and the storm intensity may be smaller. This error may be important for long-term analysis based in the ETS or EPS models.

It is recommended, for the statistics of extreme waves during storms, the use of continuous records $(\Delta t=0.5$ hours) or of $\Delta t=1$ hour, because the error is negligible.

A future work will regard the development of a new wave station for coastal zone [15], for monitoring continuous values of $H_{s}$ which will be able to investigate the individual waves in sea storms.

\section{REFERENCES}

[1] V. J. Cardone, R. E. Jensen, D. T. Resio, V. R. Swail, and A. T. Cox, "Evaluation of Contemporary Ocean Wave Models in Rare Extreme Events: The 'Halloween Storm' of October 1991 and the 'Storm of the Century' of March 1993," Journal of Atmospheric and Oceanic Technology, Vol. 13, No. 1, 1996, pp. 198-230. doi:10.1175/1520-0426(1996)013<0198:EOCOWM $>2.0$. $\mathrm{CO} ; 2$

[2] Y. Goda, "Random Seas and Design of Maritime Structures," World Scientific, 1999.

[3] M. K. Ochi, "Ocean Waves: The Stochastic Approach," Ocean Technology Series, Vol. 6, Cambridge University Press, Cambridge, 1998. doi:10.1017/CBO9780511529559

[4] P. Boccotti, "Wave Mechanics for Ocean Engineering," Elsevier Science, New York, 2000.

[5] F. Arena, "On the Prediction of Extreme Sea Waves," In: P. Zanetti, Ed., Environmental Sciences and Environmental Computing, EnviroComp Institute, Vol. 2, 2004, pp. $1-50$.

[6] F. Arena and D. Pavone, "Return Period of Nonlinear High Wave Crests," Journal of Geophysical Research:
Oceans (1978-2012), Vol. 111, No. C8, 2006 doi:10.1029/2005JC003407

[7] F. Arena and D. Pavone, "A Generalized Approach for the Long-Term Modelling of Extreme Sea Waves," Ocean Modelling, Vol. 26, No. 3-4, 2009, pp. 217-225. doi:10.1016/j.ocemod.2008.10.003

[8] L. E. Borgman, "Maximum Wave Height Probabilities for a Random Number of Random Intensity Storms," Proceedings of the 12th Conference of Coastal Engineering, Washington DC, 1970, pp. 53-64.

[9] L. E. Borgman, "Probabilities for Highest Wave in Hurricane," Journal of the Waterways, Harbors and Coastal Engineering Division, Vol. 99, No. 2, 1973, pp. 185-207.

[10] F. Fedele and F. Arena, "Long-Term Statistics and Extreme Waves of Sea Storms," Journal of Physical Oceanography, Vol. 40, No. 5, 2010, pp. 1106-1117. doi:10.1175/2009JPO4335.1

[11] G. Barbaro, "Estimating Design Wave for Offshore Structures in Italian Waters," Maritime Engineering, Vol. 164, No. 3, 2011, pp. 115-125.

[12] Rice, "Distribution of the Duration of Fades in Ration Transmission," The Bell System Technical Journal, Vol. 37, No. 3, 1958, pp. 581-635.

[13] K. Hasselmann, T. P. Barnett, E. Bouws, H. Carlson, D. E. Cartwright, E. Enke, J. A. Ewing, H. Gienapp, D. E. Hasselmann, P. Krusemann, A. Meerburg, P. Müller, D. J. Olbers, K. Richter, W. Sell and H. Walden, "Measurements of Wind-Wave Growth and Swell Decay During the Joint North Sea Wave Project (JONSWAP)," Deutsche Hydrographische Zeitschrift, Vol. A12, 1973, pp. 1-95.

[14] W. J. Pierson and L. A. Moskowitz, "A Proposed Spectral Form for Fully Developed Waves Based on the Similarity Theory of S. A. Kitaigorodskii," Journal of Geophysical Research, Vol. 69, No. 24, 1964, pp. 5181-5190. doi:10.1029/JZ069i024p05181

[15] P. Boccotti, F. Arena, V. Fiamma, A. Romolo and G. Barbaro, "Estimation of Mean Spectral Directions in Random Seas," Ocean Engineering, Vol. 38, No. 2-3, 2011, pp. 509-518. doi:10.1016/i.oceaneng.2010.11.018 